\title{
PENGARUH SIKAP WAJIB PAJAK TERHADAP KEPATUHAN WAJIB PAJAK DALAM PEMBAYARAN PAJAK BUMI DAN BANGUNAN (PBB) DI KECAMATAN MOTOLING DI KABUPATEN MINAHASA SELATAN
}

\author{
Vianny M.L. Wowor $^{1}$, Harijanto Sabijono ${ }^{2}$, Heince Wokas ${ }^{3}$ \\ ${ }^{1,2,3}$ Fakultas Ekonomi dan Bisnis, Jurusan Akuntansi, Universitas Sam Ratulangi, J1.Kampus Bahu, Manado \\ 95115, Indonesia
}

email: woworvianny@gmail.com

\begin{abstract}
Land and Property Tax is a tax system with a semi self assesment where the moreproactive and cooperative do the calculations is revenue officer, the tax payable and distribute assignment to local governments through the regional Revenue Office based on the notice of Tax Objects is filled by the Taxpayer or the verification of revenue officer on field. Consciousness to be a taxpayer who dutifully is one of obedience to the law. Compliance with the payment of taxes including a code of conduct against tax law indiscriminately and did not escape from the exception. This research aims to know attitude of the taxpayer, the influence of the existence of sanctions, fines and influence service of revenue officeragainst taxpayer compliance in payments land and property tax to the districts in Motoling. This research using quantitative research correlation methods. The results showed that the attitude of the taxpayer do not affect positively against taxpayer compliance in payments to the land and property tax. However the existence of sanctions fines and good service from revenue officer give a positive effect against the land and property tax payment compliance in district Motoling. Penalties and good service from revenue officer increase taxpayer compliance in district Motoling in payments to the land and property tax.
\end{abstract}

Key words: attitude of the taxpayers, sanctions, service of revenue officer, taxpayer compliance

\section{PENDAHULUAN}

Negara Indonesia adalah Negara hukum berdasarkan Pancasila dan Undang-undang Dasar 1945 yang menjunjung tinggi hak dan kewajiban setiap orang. Oleh karena itu, menempatkan perpajakan sebagai salah satu perwujudan kewajiban kenegaraan nasional sebagai peran serta masyarakat dalam membiayai pembangunan.

Pajak merupakan sumber penerimaan terbesar bagi suatu Negara. Peranan pajak baik sebagai sumber penerimaan dalam negeri maupun sebagai penyelaras kegiatan ekonomi pada masa-masa yang akan datang sangat penting bagi Negara kita. Untuk mewujudkannya Pemerintah melakukan upaya-upaya dibidang perpajakan mengenai kesadaran atas peran serta masyarakat sebagai wajib pajak dalam memenuhi kewajiban perpajakannya.

Pajak merupakan iuran wajib yang diberlakukan pada setiap wajib pajak atas objek pajak yang dimilikinya dan hasilnya diserahkan kepada Pemerintah. Jenis pajak yang diberlakukan di Indonesia diantaranya adalah Pajak Penghasilan, Pajak Bumi dan Bangunan, Pajak Hiburan, Pajak Reklame, Pajak Hadiah, dan lain-lain.

Pajak sebagai tulang punggung Anggaran Pendapatan dan Pembelanjaan Negara (APBN). Tanpa pajak akan sangat mustahil sekali Negara ini dapat melakukan pembangunan. Dalam struktur APBN, kontribusi penerimaan dalam negeri dari sektor pajak cukup signifikan secara nominal maupun persentase.

Penelitian ini dilaksanakan di Kecamatan Motoling. Penelitian ini didasarkan pada Kecamatan Motoling yang semakin berkembang yang mempunyai luas wilayah $56.975 \mathrm{~km}^{2}$ dengan jumlah penduduk sekitar 8.009 orang. Yang mempunyai fasilitas lapangan Sam 
Ratulangi, Pasar Tradisonal, dsb. Juga mempunyai potensi yang besar lewat hasil tanah (perkebunan) masyarakat, berupa kopra, cengkih, jagung, padi, buah-buahan, dsb. Ini mendukung meningkatnya Nilai Jual Objek Pajak (NJOP) tanah yang berada di Kecamatan Motoling. Karena dengan bertambahnya NJOP tanah berpengaruh pada peningkatan pembayaran Pajak Bumi dan Bangunan (PBB). Sehingga dapat memberikan dampak positif bagi pembangunan didaerah Kecamatan Motoling, juga Kabupaten Minahasa Selatan. Adapun tujuan yang ingin dicapai dalam penulisan ini, yaitu:

1. Untuk mengetahui pengaruh sikap wajib pajak dalam kepatuhan pembayaran PBB di Kecamatan Motoling

2. Untuk mengetahui pengaruhadanya sanksi denda PBB terhadap kepatuhan wajib pajak dalam pembayaran PBB di Kecamatan Motoling

3. Untuk mengetahui pengaruh pelayanan fiskus terhadap kepatuhan wajib pajak dalam pembayaran PBB di Kecamatan Motoling

\section{TINJAUAN PUSTAKA}

\section{Konsep Akuntansi}

Menurut Horngren, et al., dikutip oleh Winston (2013) menyatakan bahwa akuntansi adalah sistem informasi yang mengukur aktivitas bisnis, pemrosesan data menjadi laporan, dan mengkomunikasikan hasilnya pada para pengambil keputusan.Akuntansi adalah suatu sistem atau teknik dari suatu pencatatan, penggolongan dan peringkasan, pelaporan dan menganalisa data keuangan yang dilakukan dengan cara tertentu dan ukuran moneter yang dapat digunakan dalam pengambilan keputusan ekonomi atau perusahaan.

\section{Konsep Pajak}

Menurut Prof. Dr. Rochmat Soemitro, S.H (Rismawati 2015: 2) pajak adalah iuran rakyat kepada kas Negara berdasarkan undang-undang (yang dapat dipaksakan) dengan tiada mendapat jasa timbal (kontraprestasi) yang dapat ditunjukkan dan yang dapat digunakan untuk membayar pengeluaran umum.

Menurut Undang-Undang Nomor 27 Tahun 2007, pajak adalah kontribusi wajib kepada Negara yang terutang oleh orang pribadi atau badan yang bersifat memaksa berdasarkan Undang-Undang dengan tidak mendapatkan imbalan secara langsung dan digunakan untuk keperluan Negara bagi sebesar-besarnya kemakmuran rakyat.

\section{Jenis - Jenis Pajak}

Penggolongan pajak berdasarkan lembaga pemungutannya di Indonesia dapat dibedakan menjadi dua, yaitu:

1. Pajak Pusat

Merupakan pajak yang dikelola oleh Pemerintah Pusat. Segala pengadministrasian yang berkaitan dengan pajak pusat, akan dilaksanakan di Kantor Pelayanan Pajak (KPP) atau Kantor Pelayanan Penyuluhan dan Konsultasi Perpajakan (KP2KP) dan Kantor Wilayah Direktorat Jenderal Pajak (Kanwil DJP) serta diKantor Pusat Direktorat Jenderal Pajak.

2. Pajak Daerah

Merupakan pajak-pajak yang dikelola oleh Pemerintah Daerah baik ditingkat Propinsi maupun Kabupaten/Kota. Untuk pengadministrasian yang berhubungan dengan pajak daerah, akan dilaksanakan di Kantor Dinas Pendapatan Daerah atau Kantor Pajak Daerah (KPD) atau Kantor sejenisnya yang dibawahi oleh Pemerintah Daerah setempat.

\section{Fungsi Pajak}

Fungsi pajak yang paling melekat di benak kita, ketika mendengar istilah pajak adalah bahwa pajak merupakan sumber pembiayaan Negara yang terbesar. Fungsi pajak sebagai 
sumber pembiayaan ini biasa dikenal sebagai fungsi budgetair pajak. Fungsi budgetair pajak memegang peranan sangat penting di Indonesia, karena sekitar $70 \%$ pengeluaran Negara dibiayai oleh pajak

\section{Tata Cara Pemungutan Pajak}

1. Asas Pemungutan

Asas pemungutan pajak merupakan dasar-dasar yang menjadi dipungutnya pajak. Asas pemungutan pajak meliputi:

(a) Asas Domisili (asas tempat tinggal), (b).Asas Sumber, (c). Asas Kebangsaan

2. Sistem Pemungutan Pajak : Official Assesment System, Self Assesment System, With Holding System

3. Stelsel Pajak : Stelsel Nyata (riel stelsel), Stelsel Anggapan (fictieve stelsel), Stelsel Campuran

\section{Konsep Akuntansi Pajak}

Menurut Eddy Supriyanto (Graha Ilmu 2011 : 2) akuntansi pajak adalah suatu proses pencatatan dan penggolongan suatu transaksi keuangan kaitannya dengan kewajiban perpajakan dan diakhiri dengan pembuatan laporan keuangan fiskal sesuai dengan ketentuan dan peraturan perpajakan yang terkait sebagai dasar pembuatan Surat Pemberitahuan Tahunan.

Proses akuntansi perpajakan tidak jauh berbeda dengan proses akuntansi seperti biasanya. Akuntansi selalu dimulai dengan transaksi yang akan dicatat. Transaksi ini kaitannya dengan informasi keuangan yang dapat dinilai dengan uang, bukan informasi nonkeuangan.

\section{Pajak Bumi dan Bangunan}

Pajak Bumi dan Bangunan adalah pajak yang dikenakan kepada seseorang atau badan hukum yang memiliki, menguasai, memperoleh manfaat bangunan dan/atau mempunyai hak atau manfaat atas permukaan bumi.

Pajak Bumi dan Bangunan adalah pajak yang bersifat kebendaaan dalam arti besarnya pajak terutang ditentukan oleh keadaan objek yaitu bumi/tanah dan atau bangunan. Keadaan subjek (siapa yang membayar) tidak ikut menentukan besarnya pajak.

Menurut Undang-Undang Nomor 36 Tahun 2008, Pajak Penghasilan adalah pajak yang dikenakan atas penghasilan berupa gaji, upah, honorarium, tunjangan dan pembayaran lain yang diterima oleh Wajib Pajak Orang Pribadi dalam negeri sehubungan dengan pekerjaan, jasa dan kegiatan. Pajak Penghasilan merupakan pajak yang dibebankan pada penghasilan perorangan, perusahaan atau badan hukum lainnya. Pajak Penghasilan bisa diberlakukan progresif, proporsional atau regresif.

\section{Objek Pajak Bumi dan Bangunan}

a. Bumi, yaitu permukaan bumi yang meliputi tanah dan perairan pedalaman serta laut wilayah Indonesia dan tubuh bumi yang ada dibawahnya (Pasaal 1 angka 1).

b. Bangunan, adalah konstruksi teknik yang ditanam atau dilekatkan secara tetap pada tanah dan/atau perairan (Pasal 1 angka 2).

c. Objek pajak yang tidak dikenakan pajak bumi dan bangunan yaitu:

(1) Digunakan semata-mata untuk melayani kepentinan umum di bidang ibadah, sosial, kesehatan, pendidikan dan kebudayaan nasional, yang tidak dimaksudkan untuk memperoleh keuntungan

(2) Digunakan untuk kuburan, peninggalan purbakala, atau sejenis dengan itu 
(3) Merupakan hutan lindung, hutan suaka alam, hutan wisata, taman nasional, tanah penggembalaan yang dikuasai oleh desa, dan tanah Negara yang belum dibebani suatu hak

(4) Digunakan oleh perwakilan diplomatik, konsulat berdasarkan asas perlakuan timbal balik

(5) Digunakan oleh badan atau perwakilan organisasi internasional yang ditentukan oleh Menteri Keuangan

d. Objek pajak yang digunakan oleh Negara untuk penyelenggaraan pemerintahan, penentuan pengenaan pajaknya diatur lebih lanjut dengan Peraturan Pemerintah. Yang dimaksud dengan objek pajak dalam ayat ini adalah objek pajak yang dimiliki/dikuasai/digunakan oleh Pemerintah Pusat dan Pemerintah Daerah dalam menyelenggarakan pemerintahan. Mengenai bumi dan bangunan milik perseorangan dan atau bukan yang digunakan oleh Negara, kewajiban perpajakannya tergantung pada perjanjian yang diadakan.

e. Besarnya Nilai Jual Objek Pajak Tidak Kena Pajak (NJOPTKP) ditetapkan untuk masingmasing Kabupaten/Kota dengan besar setinggi-tingginya Rp. 12.000.000,00 (dua belas juta rupiah) untuk setiap Wajib Pajak. Apabila seorang Wajib Pajak mempunyai beberapa Objek Pajak, yang diberikan NJOPTKP hanya salah satu Objek Pajak yang nilainya terbesar, sedangkan Objek Pajak Lainnya tetap dikenakan secara penuh tanpa dikurangi NJOPTKP. Berdasarkan ketentuan ini Menteri Keuangan diberikan wewenang untuk mengubah besarnya Nilai Jual Objek Pajak Tidak Kena Pajak dengan mempertimbangkan perkembangan ekonomi dan moneter serta perkembangan harga umum objek pajak setiap tahunnya.

\section{Tarif Pajak}

Tarif pajak yang dikenakan atas objek pajak yaitu sebesar 0,5\% (lima per sepuluh persen). Dasar pengenaan pajak adalah Nilai Jual Objek Pajak. Besarnya Nilai Jual Objek Pajak ditetapkan setiap tiga tahun oleh Menteri Keuangan, kecuali untuk daerah tertentu ditetapkan setiap tahun sesuai perkembangan daerahnya. Dasar penghitungan pajak adalag Nilai Jual Kena Pajak yang ditetapkan serendah-rendahnya 20\% (dua puluh persen) dan setinggi-tingginya 100\% (seratus persen) dari Nilai Jual Objek Pajak. Besarnya persentase Nilai Jual Kena Pajak ditetapkan dengan Peraturan Pemerintah dengan memperhitungkan kondisi ekonomi nasional.

Besarnya pajak yang terhutang dihitung dengan cara mengalihkan tarif pajak dengan Nilai Jual Kena Pajak. Nilai Jual Pajak (assessment value) adalah nilai jual yang dipergunakan sebagai dasar penghitungan pajak, yaitu suatu persentase tertentu dari nilai jual sebenarnya.

Untuk perekonomian sekarang ini, terutama untuk tidak terlalu membebani Wajib Pajak didaerah pedesaan, tetapi dengan tetap memperhatikan penerimaan, khususnya bagi Pemerintah Daerah, maka telah ditetapkan besarnya persentase untuk menentukan besarnya NJKP.

\section{Dasar Pengenaan dan Cara Penghitungan Pajak}

a. Nilai Jual Objek Pajak

Dasar pengenaan pajak adalah Nilai Jual Objek Pajak (NJOP). Penetapan NJOP dilakukan 3 tahun sekali dan ditetapkan per wilayah berdasarkan keputusan Menteri Keuangan dengan mendengar pertimbangan Bupati/Walikota serta memperhatikan:

(1) Harga rata-rata yang diperoleh dari transaksi jual beli yang terjadi secara wajar

(2) Perbandingan harga dengan objek lain yang sejenis yang letaknya berdekatan dan fungsinya sama dan telah diketahui harga jualnya 
(3) Nilai perolehan baru

(4) Penentuan Nilai Jual Objek Pajak pengganti

Untuk menentukan besarnya NJOP yang menjadi dasar pengenaan PBB, Menteri Keuangan mengeluarkan daftar Klasifikasi dan Penetapan NJOP untuk Sektor Perkebunan, Perhutanan, Pertambangan, Pedesaan dan Perkotaan.

b. Nilai Jual Objek Pajak Tidak Kena Pajak

Adalah batas NJOP atas bumi dan/atau bangunan yang tidak kena pajak. NJOPTKP untuk setiap Wajib Pajak ditetapkan paling tinggi sebesar Rp. 24.000.000,00. Apabila seorang Wajib Pajak mempunyai beberapa Objek Pajak, yang diberikan NJOPTKP hanya salah satu Objek Pajak yang nilainya terbesar, sedangkan Objek Pajak lainnya tetap dikenakan secara penuh tanpa dikurangi NJOPTKP.

c. Nilai Jual Kena Pajak

Dasar penghitungan pajak adalah Nilai Jual Kena Pajak (NJKP) yang ditetapkan serendah-rendahnya $20 \%$ dan setinggi-tingginya $100 \%$ dari NJOP.

Besarnya persentase NJKP adalah:

- Untuk objek pajak perkebunan adalah $40 \%$

- Untuk objek pajak kehutanan adalah $40 \%$

- Untuk objek pajak pertambangan adalah $40 \%$

- Untuk objek pajak lainnya (pedesaan dan perkotaan); apabila NJOP-nya > Rp. 1.000.000.000,00 adalah 40\%; apabila NJOP-nya < Rp. 1.000.000.000,00 adalah $20 \%$

d. Penghitungan Pajak yang Terutang

Besarnya pajak yang terutang dihitung dengan cara:

(1) Menghitung NJOP bumi dan bangunan berdasarkan daftar Klasifikasi dan Penetapan NJOP untuk Sektor Perkebunan, Perhutanan, Pertambangan, Pedesaan dan Perkotaan

(2) Mengurangkan NJOPTKP dari NJOP

(3) Menghitung NJKP

(4) Mengalihkan tarif pajak dengan NJKP

\section{METODE PENELITIAN}

\section{Jenis dan sumber data}

Penelitian ini menggunakan jenis penelitian kuantitatif-kolerasional. Data yang diperoleh dari sampel populasi penelitian dianalisis sesuai dengan metode statistik yang digunakan kemudian diinterprestasikan.

Sumber data penelitian terdiri atas sumber data primer dan sumber data sekunder.

1. Data sekunder (secundary data) $\backslash$

Data sekunder merupakan sumber data penelitian yang diperoleh peneliti secara tidak langsung melalui media perantara (diperoleh dan dicatat oleh pihak lain). Data sekunder yang diperoleh dalam penelitian ini yaitu dari laporan tentang jumlah wajib pajak yang ada pada Kecamatan Motoling berserta gambaran umum tentang Kecamatan Motoling.

2. Data primer (primary data)

Data primer merupakan sumber data yang diperoleh langsung dari sumber asli (tidak melalui media perantara).

Dalam penelitian ini data primer diperoleh secara langsung dari responden melalui kuesioner yang sudah dibagikan di tiap desa yang ada di Kecamatan Motoling. 


\section{Metode Pengumpulan Data}

Pengumpulan data dilakukan untuk memperoleh informasi yang dibutuhkan dalam mencapai tujuan penelitian yang dilakukan. Dalam suatu penelitian, langkah pengumpulan data merupakan suatu tahap yang sangat menentukan terhadap proses dan hasil penelitian yang akan dilakukan.

Metode pengumpulan data yang digunakan dalam penelitian ini, yaitu:

1. Observasi, yaitu mengamati secara langsung kondisi dan situasi yang ada di Kecamatan Motoling.

2. Kuisioner, yaitu mengumpulkan data dengan membuat pertanyaan dan pernyataan tertulis kepada responden yang ada di Kecamatan Motoling dalam hal ini para Wajib Pajak PBB.

3. Studi kepustakaan, yaitu untuk melengkapi data-data yang ada, penulis melakukan penelitian melalui buku-buku, karya ilmiah, ensiklopedia, internet guna mendapatkan landasan teori dan alat analisis yang sesuai dalam memecahkan masalah yang akan dibahas.

\section{Metode analisis Data}

Metode analisis data dalam penelitian ini menggunakan software SPSS dengan lima tahap. Pertama, statisitik deskriptif. Tahap kedua, pengujian kualitas data. Tahap ketiga, melakukan uji penyimpangan asumsi klasik. Tahap keempat, melakukan analisis regresi berganda. Dan tahap kelima, melakukan pengujian hipotesis.

\section{Analisis Regresi Berganda}

Wibowo (2012) mengemukakan model regresi linear berganda dengan sendirinya menyatakan suatu bentuk hubungan linear antara dua atau lebih variabel independen dengan variabel dependennya. Adapun model regresi berganda dalam penelitian ini adalah sebagai berikut:

$$
\mathbf{Y}=\alpha+\boldsymbol{\beta}_{1} \mathbf{X}_{1}+\boldsymbol{\beta}_{2} \mathbf{X}_{2}+\boldsymbol{\beta}_{3} \mathbf{X}_{3+} \varepsilon
$$

Keterangan :

$$
\begin{array}{ll}
\mathbf{Y} & =\text { Kepatuhan wajib pajak dalam pembayaran PBB } \\
\boldsymbol{\alpha} & =\text { Konstanta } \\
\boldsymbol{\beta} & =\text { Koefisien regresi } \\
\mathbf{X}_{\mathbf{1}} & =\text { Sikap wajib pajak terhadap prioritas pembangunan daerah } \\
\mathbf{X}_{\mathbf{2}} & =\text { Sikap wajib pajak tentang pembayaran sanksi denda PBB } \\
\mathbf{X}_{\mathbf{3}} & =\text { Sikap wajib pajak terhadap pelayanan fiskus } \\
\boldsymbol{\varepsilon} & =\text { Error of estimation }
\end{array}
$$

\section{Pengujian Hipotesis}

Pengujian hipotesis dilakukan untuk mengetahui gambaran mengenai pengaruh variabel bebas pada variabel terikat (Ghozali, 2013:96). Pengujian hipotesis dalam penelitian ini dilakukan untuk hal-hal berikut ini:

\section{Koefisien Determinasi $\left(\mathrm{R}^{2}\right)$}

Nilai koefisien determinasi digunakan untuk mengetahui seberapa jauh kemampuan model dalam menerangkan variabel dependen. (Ghozali, 2013:97). Nilai koefisien determinasi adalah antara nol dan satu. Nilai $\mathrm{R}^{2}$ yang kecil berarti kemampuan variabelvariabel independen dalam menjelaskan variasi variabel dependen amat terbatas. Nilai yang mendekati satu berarti variabel-variabel independen memberikan hampir semua informasi yang dibutuhkan untuk memprediksi variasi variabel dependen.

2. Uji Kelayakan Model (F Test) 
Uji ini bertujuan untuk memprediksi hubungan antar variabel. Apabila $\mathrm{p}$ value $\leq 5 \%$ maka model dinyatakan layak. Dalam penelitian ini uji $\mathrm{F}$ untuk menguji variabel secara serentak atau bersama-sama. ANOVA (Analysis of Variance) dapat digunakan untuk uji signifikansi simultan. Untuk menjawab masalah, mencapai tujuan dan pembuktian hipotesis serta untuk mengetahui apakah variabel eksplanatori secara parsial berpengaruh secara signifikan (nyata) terhadap variabel terikat, maka perlu dilakukan uji t. Sementara uji F digunakan untuk melihat apakah semua variabel signifikan.

3. Uji Signifikansi Parameter Individual (T test)

Uji ini dilakukan untuk mengetahui tingkat pengaruh variabel bebas dalam menerangkan variasinya pada variabel terikat (Ghozali, 2013:98). Apabila nilai signifikansi (sig) $\leq 5 \%$ maka hipotesis diterima, dan sebaliknya apabila nilai sig $>5 \%$, maka hipotesis akan ditolak. Dalam penelitian ini hasil uji T untuk mengukur pengaruh variabel bebas secara parsial atau sendiri-sendiri.

\section{HASIL ANALISIS DAN PEMBAHASAN}

\section{Hasil analisis}

Motoling adalah sebuah kecamatan di Kabupaten Minahasa Selatan, Sulawesi Utara, Indonesia. Ibu kotaKecamatan Motoling adalah Motoling Maesa dan Pusat Pemerintahan berada di desa Motoling Stat.

Kecamatan Motoling dahulu merupakan kecamatan terbesar di Indonesia dengan jumlah desa sebanyak 27 desa (sesuai perhitungan pada waktu itu) yang kemudian dimekarkan menjadi 5 kecamatan yakni Ranoyapo, Motoling, Motoling Barat, Kumelembuai, dan Motoling Timur.

Berdasarkan hasil tabulasi yang diolah dengan menggunakan program SPSS 22.0 menghasilkan deskripsi statistik variabel penelitian seperti pada tabel 4.1 berikut.

Tabel 4.1

Descriptive Statistics

\begin{tabular}{|c|r|r|r|r|r|}
\hline & $\mathrm{N}$ & Minimum & Maximum & Mean & Std. Deviation \\
\hline X1 & 41 & 9 & 30 & 23.34 & 5.028 \\
X2 & 41 & 7 & 30 & 23.73 & 4.353 \\
X3 & 41 & 5 & 25 & 17.29 & 4.326 \\
Y & 41 & 10 & 29 & 22.44 & 4.031 \\
Valid N (listwise) & 41 & & & & \\
\hline
\end{tabular}

Sumber : Hasil Output SPSS 22 (2016)

Dilihat dari tabel 4.1 dapat dilihat bahwa:

1. Untuk variabel bebas $\left(\mathrm{X}_{1}\right)$ diperoleh rata-rata hitung Sikap Wajib Pajak sebesar 23.34 dengan standar deviasi 5.028 dan $\mathrm{N}$ sebanyak 41.

2. Untuk variabel bebas $\left(\mathrm{X}_{2}\right)$ diperoleh rata-rata hitung Sanksi Denda PBB sebesar 23.73 dengan standar deviasi 4.353 dan $\mathrm{N}$ sebanyak 41.

3. Untuk variabel bebas $\left(\mathrm{X}_{3}\right)$ diperoleh rata-rata hitung Pelayanan Fiskus sebesar 17.29 dengan standar deviasi 4.326 dan $\mathrm{N}$ sebanyak 41.

4. Untuk variabel terikat $\left(\mathrm{Y}_{2}\right)$ diperoleh rata-rata hitung Kepatuhan Wajib Pajak dalam Pembayaran PBB sebesar 22.44 dengan standar deviasi 4.031 dan N sebanyak 41.

Uji validitas dimaksudkan untuk mengukur sah atau valid tidaknya suatu kuisioner. Uji validitas yang digunakan adalah dengan melakukan kolerasi bilvariate antara masing-masing skor indikator dengan total skor konstruk. 
Ringkasan hasil uji validitas dapat dilihat pada Tabel 4.2 berikut.

Tabel 4.2

Hasil Uji Validitas

\begin{tabular}{|c|c|c|c|c|}
\hline Indikator & Pearson Correlation & Signifikansi & $\mathrm{N}$ & Keterangan \\
\hline $\begin{array}{c}\text { Variabel Sikap } \\
\text { Wajib Pajak }\left(\mathbf{X}_{\mathbf{1}}\right) \\
\text { Pertanyaan } 1 \\
\text { Pertanyaan } 2 \\
\text { Pertanyaan } 3 \\
\text { Pertanyaan } 4 \\
\text { Pertanyaan } 5 \\
\text { Pertanyaan } 6\end{array}$ & $\begin{array}{l}0.885 \\
0.906 \\
0.945 \\
0.843 \\
0.819 \\
0.852\end{array}$ & $\begin{array}{l}0.000 \\
0.000 \\
0.000 \\
0.000 \\
0.000 \\
0.000\end{array}$ & $\begin{array}{l}41 \\
41 \\
41 \\
41 \\
41 \\
41\end{array}$ & $\begin{array}{l}\text { Valid } \\
\text { Valid } \\
\text { Valid } \\
\text { Valid } \\
\text { Valid } \\
\text { Valid }\end{array}$ \\
\hline $\begin{array}{c}\text { Variabel Sanksi } \\
\text { Denda }\left(\mathbf{X}_{\mathbf{2}}\right) \\
\text { Pertanyaan } 1 \\
\text { Pertanyaan } 2 \\
\text { Pertanyaan } 3 \\
\text { Pertanyaan } 4 \\
\text { Pertanyaan } 5 \\
\text { Pertanyaan } 6\end{array}$ & $\begin{array}{l}0.787 \\
0.823 \\
0.661 \\
0.743 \\
0.602 \\
0.706\end{array}$ & $\begin{array}{l}0.000 \\
0.000 \\
0.000 \\
0.000 \\
0.000 \\
0.000\end{array}$ & $\begin{array}{l}41 \\
41 \\
41 \\
41 \\
41 \\
41\end{array}$ & $\begin{array}{l}\text { Valid } \\
\text { Valid } \\
\text { Valid } \\
\text { Valid } \\
\text { Valid } \\
\text { Valid }\end{array}$ \\
\hline $\begin{array}{c}\text { Variabel } \\
\text { Pelayanan Fiskus } \\
\left(\mathbf{X}_{\mathbf{3}}\right) \\
\text { Pertanyaan 1 } \\
\text { Pertanyaan } 2 \\
\text { Pertanyaan } 3 \\
\text { Pertanyaan } 4 \\
\text { Pertanyaan } 5\end{array}$ & $\begin{array}{l}0.862 \\
0.744 \\
0.779 \\
0.820 \\
0.856\end{array}$ & $\begin{array}{l}0.000 \\
0.000 \\
0.000 \\
0.000 \\
0.000\end{array}$ & $\begin{array}{l}41 \\
41 \\
41 \\
41 \\
41\end{array}$ & $\begin{array}{l}\text { Valid } \\
\text { Valid } \\
\text { Valid } \\
\text { Valid } \\
\text { Valid }\end{array}$ \\
\hline $\begin{array}{c}\text { Variabel } \\
\text { Kepatuhan Wajib } \\
\text { Pajak (Y) } \\
\text { Pertanyaan 1 } \\
\text { Pertanyaan 3 } \\
\text { Pertanyaan } 4 \\
\text { Pertanyaan 5 } \\
\text { Pertanyaan 6 }\end{array}$ & $\begin{array}{l}0.846 \\
0.868 \\
0.882 \\
0.868 \\
0.827\end{array}$ & $\begin{array}{l}0.000 \\
0.000 \\
0.000 \\
0.000 \\
0.000\end{array}$ & $\begin{array}{l}41 \\
41 \\
41 \\
41 \\
41\end{array}$ & $\begin{array}{l}\text { Valid } \\
\text { Valid } \\
\text { Valid } \\
\text { Valid } \\
\text { Valid }\end{array}$ \\
\hline
\end{tabular}

Sumber : Hasil Output SPSS 22 (2016)

Hasil perhitungan uji t dapat dilihat pada Tabel 4.9 berikut. 


\section{Tabel 4.9}

Hasil Uji t

Coefficients $^{\mathrm{a}}$

\begin{tabular}{|c|c|c|c|c|c|}
\hline \multirow[b]{2}{*}{ Model } & \multicolumn{2}{|c|}{$\begin{array}{c}\text { Unstandardized } \\
\text { Coefficients }\end{array}$} & \multirow{2}{*}{$\begin{array}{c}\text { Standardized } \\
\text { Coefficients } \\
\text { Beta }\end{array}$} & \multirow[b]{2}{*}{$t$} & \multirow[b]{2}{*}{ Sig. } \\
\hline & $\mathrm{B}$ & $\begin{array}{l}\text { Std. } \\
\text { Error }\end{array}$ & & & \\
\hline (Constant) & 5.291 & 2.125 & & 2.490 & .017 \\
\hline Sikap Wajib Pajak & .034 & .106 & .042 & .319 & .752 \\
\hline Pemahaman Sanksi Denda & .422 & .154 & .456 & 2.737 & .009 \\
\hline Pelayanan Fiskus & .367 & .131 & .393 & 2.794 & .008 \\
\hline
\end{tabular}

Sumber : Hasil Output SPSS 22 (2016)

1. Pengujian Hipotesis Pertama $\left(\mathrm{H}_{1}\right)$

Variabel Sikap Wajib Pajak, $t_{\text {hitung }} 0,319$ dan $t_{\text {tabel }}=1.68288$ dan nilai signifikansi $0,752>0,05$. Karena $t_{\text {hitung }}<t_{\text {tabel }}$ dan nilai sig. $>0,05$ dapat disimpulkan bahwa hipotesis pertama $\left(\mathrm{H}_{1}\right)$ ditolak. Hal ini menjelaskan bahwa variabel Sikap Wajib Pajak $\left(\mathrm{X}_{1}\right)$ tidak berpengaruh terhadap variabel Kepatuhan Wajib Pajak dalam Pembayaran PBB.

2. Pengujian Hipotesis Kedua $\left(\mathrm{H}_{2}\right)$

Nilai untuk variabel akan adanya Sanksi Denda, $t_{\text {hitung }}=2,737$ dan $t_{\text {tabel }}=1.68288$ dan nilai signifikansi $0,009<0,05$. Karena $t_{\text {hitung }}>t_{\text {tabel }}$ dan nilai sig. $<0,05$ dapat disimpulkan bahwa hipotesis kedua $\left(\mathrm{H}_{2}\right)$ diterima. Hal ini menjelaskan tentang pengaruh positif antara variabel akan adanyaSanksi Denda $\left(\mathrm{X}_{2}\right)$ terhadap Kepatuhan Wajib Pajak dalam Pembayaran PBB.

3. Pengujian Hipotesis Ketiga $\left(\mathrm{H}_{3}\right)$

Nilai variabel Pelayanan Fiskus, $t_{\text {hitung }}=2,794$ dan $t_{\text {tabel }}=1.68288$, nilai signifikansi $0,008<0,05$. Karena $t_{\text {hitung }}>t_{\text {tabel }}$ dan nilai sig. $<0,05$ dapat disimpulkan bahwa hipotesis ketiga $\left(\mathrm{H}_{3}\right)$ diterima. Hal ini menjelaskan tentang pengaruh positif antara variabel Pelayanan Fiskus $\left(\mathrm{X}_{3}\right)$ terhadap Kepatuhan Wajib Pajak dalam Pembayaran PBB.

\section{Pembahasan}

Berdasarkan pengujian hipotesis menunjukkan bahwa sikap wajib pajak terhadap kepatuhan wajib pajak membayar PBB tidak berpengaruh sebesar 0,319 dengan tingkat signifikansi 0,752 , yang berarti tidak signifikan karena berada diatas syarat nilai signifikansi yaitu 0,05. Sehingga dapat disimpulkan bahwa sikap wajib pajak tidak meningkatkan kepatuhan wajib pajak dalam pembayaran PBB.

Hasil penelitian ini sama dengan penelitian dari Vanli (2016) di Kelurahan Tara-Tara kota Tomohon, yang menunjukkan juga sikap wajib pajak tidak berpengaruh secara signifikan terhadap kepatuhan wajib pajak dalam pembayaran PBB. Dibutuhkan pemeriksaan pajak yang lebih detail dan serius untuk meningkatkan kepatuhan wajib pajak dalam pembayaran $\mathrm{PBB}$.

Berbeda dengan penelitian dari Khoirul (2011) di Kelurahan Tembalang Semarang, sikap wajib pajak berpengaruh secara positif terhadap kepatuhan wajib pajak dalam pembayaran PBB. Kesadaran sikap wajib pajak sangat berpengaruh dalam kepatuhan pembayaran $\mathrm{PBB}$.

Berdasarkan pengujian hipotesis menunjukkan bahwa adanya sanksi denda terhadap kepatuhan wajib pajak dalam membayar PBB berpengaruh positif sebesar 2,737 pada tingkat signifikansi 0,009 , yang berarti signifikan karena berada dibawah syarat nilai signifikansi 
yaitu 0,05 . Sehingga dapat disimpulkan bahwa adanya sanksi denda dapat meningkatkan kepatuhan wajib pajak dalam membayar PBB.

Kebijakan akan adanya sanksi denda sangatlah bermanfaat dalam upaya peningkatan kepatuhan wajib pajak dalam membayar PBB. Bilamana wajib pajak tidak membayar pajak, maka akan dikenakan sanksi denda. Wajib pajak akan mematuhi pembayaran PBB ketika melihat akan adanya sanksi denda yang lebih banyak merugikan ketika tidak membayar pajak.

Berdasarkan pengujian hipotesis menunjukkan bahwa sikap wajib pajak terhadap pelayanan fiskus dalam kepatuhan wajib pajak membayar PBB berpengaruh positif sebesar 2,794 dengan tingkat signifikansi 0,008 , yang artinya signifikan karena berada dibawah syarat nilai signifikansi yaitu 0,05 . Sehingga dapat disimpulkan bahwa pelayanan fiskus dapat meningkatkan kepatuhan wajib pajak membayar PBB.

Sikap wajib pajak dalam memenuhi kewajibannya membayar pajak tergantung pada mutu pelayanan yang diberikan oleh petugas pajak. Ketika seorang fiskus mempunyai keahlian yang kompeten dalam pengetahuan dan pengalaman akan kebijakan perpajakan, administrasi perpajakan, dan peraturan UU Perpajakan. Maka kepatuhan wajib pajak dalam membayar pajak akan lebih meningkat.

\section{KESIMPULAN DAN SARAN}

\section{Kesimpulan}

Berdasarkan hasil pembahasan sebelumnya, maka dapat disimpulkan bahwa:

1. Nilai dari variabel $X_{1}$ (sikap wajib pajak) tidak berpengaruh secara positif terhadap kepatuhan wajib pajak dalam pembayaran PBB. Sikap wajib pajak tidak meningkatkan kepatuhan wajib pajak dalam pembayaran PBB.

2. Nilai dari variabel $\mathrm{X}_{2}$ (sanksi denda) mempengaruhi secara positif terhadap kepatuhan wajib pajak dalam pembayaran PBB. Adanya sanksi denda dapat meningkatkan kepatuhan wajib pajak dalam pembayaran PBB.

3. Nilai dari variabel $\mathrm{X}_{3}$ (pelayanan fiskus) mempengaruhi secara positif terhadap kepatuhan wajib pajak dalam pembayaran PBB. Pelayanan fiskus yang baik dapat meningkatkan kepatuhan wajib pajak dalam pembayaran PBB.

\section{Saran}

1. Untuk para aparat fiskus agar dapat meningkatkan lagi mutu pelayanan yang kompeten. Lebih memperluas pengetahuan wajib pajak tentang kesadarannya dalam membayar pajak, misalnya dengan lebih banyak lagi melakukan penyuluhanpenyuluhan tentang perpajakan sampai ke pelosok-pelosok desa yang ada di Kecamatan Motoling.

2. Untuk para peneliti selanjutnya yang tertarik akan bidang perpajakan khususnya PBB, agar dapat menindak lanjuti penelitian ini dengan menambah jumlah sampel, jumlah variabel, dan mengambil objek lain.

\section{DAFTAR PUSTAKA}

Abdul, Abubakari. 2013. Evaluating taxpayers attitude and its influence on tax compliance decisions in Tamale, Ghana. Journal of Accounting and Taxation. University in Tamale, Ghana. http://www.academicjournals.org/journal/JAT/article-full-textpdf/ED937DB41302

Ananda, 2015. Faktor-faktor yang mempengaruhi kepatuhan wajib pajak dalam membayar Pajak Bumi dan Bangunan dengan pendapatan masyarakat sebagai variabel 
moderating di Kota Medan. Universitas Sumatera Utara, Medan. http://balitbang.pemkomedan.go.id/tinymcpuk/gambar/file/Ananda(1).pdf

Anugerah, Prisma. 2016. Partisipasi masyarakat dalam melakukan pembayaran Pajak Bumi dan Bangunan Perdesaan dan Perkotaan di Kecamatan Palaran Kota Samarinda. Universitas Mulawarman, Samarinda. http://ejournal.an.fisip-unmul.ac.id/site/wpcontent/uploads/2016/08/Jurnal\%20EDIT\%20(08-18-16-02-37-26).pdf

Ariwirawan, Surya. 2014. Analisis Implementasi dan Peranan Pajak Bumi dan Bangunan Perkotaan Pedesaan (PBB P-2) dan Bea Perolehan Hak Atas Tanah dan Bangunan (BPHTB) di Kabupaten Sinjai. Universitas Hasanuddin, Makassar. http://repository.unhas.ac.id/handle/123456789/8976

Artha, Permana. 2016. Analisis kepatuhan wajib Pajak Bumi dan Bangunan (PBB) di Sedahan Kecamatan Seririt Tahun 2011-2015. Universitas Pendidikan Ganesha, Singaraja. http://ejournal.undiksha.ac.id/index.php/JJPE/article/viewFile/7219/4928

Christmas, Merry. 2015. Analisis Pemungutan dan Pencatatan Akuntansi PBB Perdesaan dan Perkotaan (PBB-P2) sebagai Pajak Daerah Di Kota Tomohon. Universitas Sam Ratulangi,

Manado. https://webcache.googleusercontent.com/search?q=cache:DOPRGI8Dx4MJ:https://ejou rnal.unsrat.ac.id/index.php/emba/article/view/8360+\&cd=1\&hl=en\&ct=clnk\&client=fir efox-b-ab. Diakses pada 17 November 2015

EMBA. 2013. Buku Panduan Penulisan Skripsi Dan Artikel-Tahun 2013. Fakutas Ekonomi Dan Bisnis. Universitas Sam Ratulangi, Manado.

Harmawati, Ni Komang Ayu. 2016. Pengaruh pemahaman perpajakan, kualitas pelayanan, ketegasan sanksi pajak dan pemeriksaan pajak pada kepatuhan wajib pajak PBB-P2 dengan tingkat pendidikan sebagai pemoderasi. Universitas Udayana, Denpasar. https://ojs.unud.ac.id/index.php/EEB/article/view/17042

Helhel, Ahmed. 2014. Factors Affecting Tax Attitudes and Tax Compliance: A Survey Study in Yemen. University in Antalya, Turkey https://www.researchgate.net/profile/Yesim_Helhel/publication/270338082_Factors_Af fecting_Tax_Attitudes_and_Tax_Compliance_A_Survey_Study_in_Yemen/links/54a91 b920cf256bf8bb7f5b4.pdf

Kuria, John. 2016. Taxpayers' Attitudes And Tax Compliance Behaviour In Kenya. United States International University, Kenya. http://www.iosrjournals.org/iosr$\mathrm{jbm} /$ papers/Vol18-issue6/Version-2/J1806026170.pdf

Labantu, Haris. 2013. Analisis prosedur pemungutan PBB P2 Kabupaten Minahasa di Kantor Pelayanan Pajak Pratama Bitung. Universitas Sam Ratulangi, Manado. https://webcache.googleusercontent.com/search?q=cache:zjk6PEEu2ywJ:https://ejourna l.unsrat.ac.id/index.php/emba/article/download/1897/1505+\&cd=1\&hl=en\&ct=clnk\&cli ent=firefox-b-ab

Mardiasmo, 2011. Perpajakan. Andi, Yogyakarta.

Musthofa, Khoirul. 2011. Pengaruh penghasilan dan kesadaran wajib pajak terhadap kepatuhan dalam membayar Pajak Bumi dan Bangunan (PBB) di Kelurahan Tembalang Semarang tahun 2009. Universitas Negeri, Semarang. http://lib.unnes.ac.id/10284/1/10133.pdf

Napitulu, Lucia Silveria. 2015. Pelaksanaan Pajak Bumi dan Bangunan Pedesaan dan Perkotaan (PBB P-2) sebagai Pajak Daerah dan implikasi terhadap Pencatatan Akuntansi pada Pemerintah Kota Manado. Universitas Sam Ratulangi, Manado. http://download.portalgaruda.org/article.php?article=292088\&val=1025\&title=PAJAK $\%$ 20BUMI\%20DAN\%20BANGUNAN\%20PERDESAAN\%20DAN\%20PERKOTAA N\%20(PBBP2)\%20SEBAGAI\%20PAJAK\%20DAERAH\%20DAN\%20IMPLIKASIN 
YA\%20TERHADAP\%20PENCATATAN\%20AKUNTANSI\%20\%20PADA\%20PEM ERINTAH\%20KOTA\%20MANADO

Nisa, Hairun. 2016. Studi tentang pelaksanaan pemungutan Pajak Bumi dan Bangunan di Dinas Pendapatan Daerah Kota Samarinda. Universitas Mulawarman, Samarinda. http://ejournal.an.fisip-unmul.ac.id/site/wpcontent/uploads/2016/07/Jurnal\%20HAIRUN\%20NISA\%20(07-29-16-05-24-21).pdf

Peter, Osebe Rawlings. 2014. Analysis of Factors Affecting Tax Compliance in Real Estate Sector: A Case of Real Estate Owners in Nakuru Town, Kenya. Kabarak University, Kenya. http://www.iiste.org/Journals/index.php/RJFA/article/download/13523/14240

Sapiei, Noor Sharoja. 2014. Determinants of tax compliance behaviour of corporate taxpayers in Malaysia. University of New South Wales, Australia. https://www.business.unsw.edu.au/research-site/publications-site/ejournaloftaxresearchsite/Documents/05_SapieiKasipillaiEze_TaxComplianceMalaysia.pdf

Suciningsih, Kadek. 2015. Pengaruh Sanksi Perpajakan dan Kesadaran Wajib Pajak Terhadap Kualitas Pelayanan Serta Dampaknya Pada kepatuhan Wajib Pajak Dalam Membayar Pajak Bumi dan Bangunan di Dinas Pendapatan Daerah Kabupaten Buleleng. Universitas Pendidikan Ganesha, Singaraja. http://ejournal.undiksha.ac.id/index.php/JJM/article/download/4838/3655

Sudirman Rismawati dan Amiruddin Antong, 2015. Perpajakan (Pendekatan Teori dan Praktek). Empat Dua Media, Malang.

Supriyanto Eddy, 2011. Akuntansi Perpajakan, Edisi Pertama Cetakan Pertama. Graha Ilmu, Yogyakarta.

Suwardjono, 2010. Akuntansi Perpajakan, Edisi Ketiga Cetakan Keempat. BPFE, Yogyakarta.

Tanoto, Shanti Ananda. 2016. Analisis sebelum dan sesudah penerapan e-payment terhadap penerimaan Pajak Bumi dan Bangunan Pedesaan dan Perkotaan (PBB-P2) pada Kabupaten dan Kota di Provinsi Lampung. Universitas Lampung, Bandar Lampung. http://digilib.unila.ac.id/22419/3/SKRIPSI\%20TANPA\%20BAB\%20PEMBAHASAN. pdf

TMbooks, 2013. Perpajakan (Esensi dan Aplikasi). Andi, Yogyakarta.

Tuwo, Vanli. 2016. Pengaruh sikap dan kesadaran wajib pajak terhadap kepatuhan wajib Pajak Bumi dan Bangunan di kelurahan Tara-Tara Kota Tomohon. Universitas Sam Ratulangi, Manado. https://media.neliti.com/media/publications/2884-ID-pengaruhsikap-dan-kesadaran-wajib-pajak-terhadap-kepatuhan-wajib-pajak-bumi-dan.pdf

Utiarahman, Nur Riza. 2016. Analisis efektivitas dan kontribusi penerimaan Pajak Bumi dan Bangunan Perdesaan Perkotaan (PBB-P2) terhadap Pendapatan Asli Daerah (PAD) Kota Tomohon. Universitas Sam Ratulangi, Manado. https://ejournal.unsrat.ac.id/index.php/jbie/article/view/12384 